\title{
Fosmids of novel marine Planctomycetes from the Namibian and Oregon coast upwelling systems and their cross-comparison with planctomycete
} genomes

Dagmar Woebken ${ }^{1}$, Hanno Teeling 2 , Patricia Wecker ${ }^{2,3}$, Alexandra Dumitriu ${ }^{3}$, Ivaylo Kostadinov ${ }^{2,3}$, Edward F DeLong ${ }^{4}$, Rudolf Amann ${ }^{1}$ and Frank O Glöckner ${ }^{2,3}$ ${ }^{1}$ Department of Molecular Ecology, Max Planck Institute for Marine Microbiology, Bremen, Germany; ${ }^{2}$ Microbial Genomics Group, Max Planck Institute for Marine Microbiology, Bremen, Germany; ${ }^{3}$ School of Engineering and Sciences, Jacobs University Bremen gGmbH, Bremen, Germany and ${ }^{4}$ Division of Biological Engineering \& Department of Civil and Environmental Engineering, Massachusetts Institute of Technology, Cambridge, MA, USA

\begin{abstract}
Planctomycetes are widely distributed in marine environments, where they supposedly play a role in carbon recycling. To deepen our understanding about the ecology of this sparsely studied phylum six planctomycete fosmids from two marine upwelling systems were investigated and compared with all available planctomycete genomic sequences including the as yet unpublished nearcomplete genomes of Blastopirellula marina DSM $3645^{\top}$ and Planctomyces maris DSM $8797^{\top}$. High numbers of sulfatase genes (41-109) were found on all marine planctomycete genomes and on two fosmids (2). Furthermore, C1 metabolism genes otherwise only known from methanogenic Archaea and methylotrophic Proteobacteria were found on two fosmids and all planctomycete genomes, except for 'Candidatus Kuenenia stuttgartiensis'. Codon usage analysis indicated high expression levels for some of these genes. In addition, novel large families of planctomycete-specific paralogs with as yet unknown functions were identified, which are notably absent from the genome of 'Candidatus Kuenenia stuttgartiensis'. The high numbers of sulfatases in marine planctomycetes characterizes them as specialists for the initial breakdown of sulfatated heteropolysaccharides and indicate their importance for recycling carbon from these compounds. The almost ubiquitous presence of $\mathrm{C} 1$ metabolism genes among Planctomycetes together with codon usage analysis and information from the genomes suggest a general importance of these genes for Planctomycetes other than formaldehyde detoxification. The notable absence of these genes in Candidatus $\mathrm{K}$. stuttgartiensis plus the surprising lack of almost any planctomycete-specific gene within this organism reveals an unexpected distinctiveness of anammox bacteria from all other Planctomycetes.
\end{abstract}

The ISME Journal (2007) 1, 419-435; doi:10.1038/ismej.2007.63; published online 9 August 2007

Subject Category: integrated genomics and post-genomics approaches in microbial ecology

Keywords: Blastopirellula marina; C1 metabolism genes; Planctomyces maris; Planctomycete; marine upwelling; sulfatase genes

\section{Introduction}

Upwelling in marine coastal regions is a common phenomenon, which can, for example, be caused by

Correspondence: H Teeling, Microbial Genomics Group, Max Planck Institute for Marine Microbiology, Celsiusstrasse 1, Bremen 28359, Germany.

E-mail: hteeling@mpi-bremen.de

Received 7 May 2007; revised 26 June 2007; accepted 27 June 2007; published online 9 August 2007 alongshore winds that drive surface water away from the shore and bring nutrient-rich deep-sea water to the sun-lit surface. This results in an enhanced primary production, and the mineralization of the high amounts of biomass in marine upwelling systems results in depletion of oxygen in deeper waters forming the so-called oxygen minimum zone (OMZ). Massive losses of fixed nitrogen occur in the OMZ, mainly caused by planctomycetes living via anammox-the comproportionation of nitrite and ammonia to dinitrogen gas (Kuypers 
et al., 2005). Planctomycetes are also part of the microbial communities that are attached to macroscopic detrital aggregates (DeLong et al., 1993; Crump et al., 1999), where they are likely involved in the breakdown of complex heteropolysaccharides (Glöckner et al., 2003). Such marine snow particles play a major role in highly productive marine ecosystems like upwelling regions.

These observations notwithstanding, the overall ecological functions of the Planctomycetes are not well studied and hence not well understood. This might be attributed to the fact that in terms of abundance, Planctomycetes do not belong to the major players in marine surface waters. Typically, they amount only for a few percent of the total microbial biomass in coastal waters, and even much less in the marine pelagial (Rusch et al., 2007), while abundances are much higher in marine sediments (Rusch et al., 2003; Inagaki et al., 2006; Musat et al., 2006). However, it was recently shown that during diatom blooms in Oregon coastal waters Pirellularelated planctomycetes can reach cell numbers as high as $4 \times 10^{7} 1^{-1}$. Since these planctomycetes have often been observed to be directly associated with algae, a direct interaction and carbon flow between algae and planctomycetes has been presumed (Morris et al., 2006). Moreover, abundances do not necessarily equal importance. Key metabolisms can be performed by minor groups, as we have learned from the long-neglected anammox planctomycetes, which have been shown to play such an important role in the global nitrogen cycle. Previous studies have indicated that other groups of marine planctomycetes are specialized on the initial breakdown of highly complex carbohydrates, thereby making them accessible to other organisms, and thus may play an important role in global carbon cycle (Glöckner et al., 2003).

In general, the Planctomycetes constitute an independent phylum within the domain Bacteria (Woese, 1987), consisting of only one single family (Planctomycetaceae) with six accepted (Rhodopirellula, Blastopirellula, Pirellula, Planctomyces, Isosphaera, Gemmata) (Schlesner et al., 2004) and four candidate genera (Kuenenia, Brocadia, Scalindua, Anammoxoglobus). The phylogeny of the Planctomycetes has been under debate for some time with conflicting views of them as being either rapidly evolving (Woese, 1987; Fuerst, 1995), deep (Stackebrandt et al., 1984) or even deepest branching within the bacterial domain (Brochier and Philippe, 2002) or being remotely related to the Chlamydiae (Weisburg et al., 1986; Liesack et al., 1992; Teeling et al., 2004). Recent studies suggest that the Planctomycetes are part of the so-called PVC superphylum, a monophyletic clade that besides the Planctomycetes is formed by the phyla Chlamydiae, Verrucomicrobia, Lentisphaerae, and the candidate phyla 'Poribacteria' and OP3 (the last two of which have no cultured representatives so far) (Fieseler et al., 2004; Wagner and Horn, 2006).
All Planctomycetes known to date are characterized by a unique set of characteristic morphological features. Their cells are organized in a polar manner within some non-prosthecate appendages (stalks) or polar holdfast structures. In addition, planctomycete cells have a generative pole from which daughter cells are produced in a yeast-like budding process (Fuerst, 1995). A life cycle has been described for some planctomycetes that resembles that of Caulobacter crescentus with flagellated, non-reproductive swarmer cells and non-motile but reproductive adult cells (Tekniepe et al., 1981; Franzmann and Skerman, 1984; Fuerst, 1995; Glöckner et al., 2003). The cell walls of Planctomycetes lack the common bacterial cell wall constituent peptidoglycan, but instead appear in some species to consist of proline and cystein-rich proteins that are stabilized by disulfide cross-links (König et al., 1984; Liesack et al., 1986). Likewise, S-layer-like arrayed proteins have been reported (Jetten et al., 2002). The cytoplasmic membranes of planctomycetes contain characteristic pore-like crateriform structures that are either evenly distributed over the whole surface (genus Planctomyces) or confined around the reproductive cell pole (genus Pirellula) (Liesack et al., 1986). In addition, the DNA of planctomycetes is highly compacted and hence often visible on electron micrographs as so-called nucleoids.

The most distinctive feature of the Planctomycetes, however, is their internal compartmentalization (Lindsay et al., 1997, 2001; Fuerst, 2005). Representatives of the genera Rhodopirellula, Blastopirellula, Pirellula, Planctomyces and Isosphera have been shown to contain a single, large, membrane-bounded compartment, termed the pirellulosome in Pirellula species. Additional structures have been reported for Gemmata obscuriglobus UQM $2246^{\mathrm{T}}$ and the anammox planctomycete 'Candidatus Brocadia anammoxidans' (Lindsay et al., 2001). G. obscuriglobus UQM $2246^{\mathrm{T}}$ has an additional double-membrane-bounded compartment enclosing its nucleoid and Candidatus Brocadia anammoxidans a special compartment, termed the anammoxosome. The anammoxosome's membrane contains unique ladderane lipids (Sinninghe Damsté et al., 2002), and has been proposed to separate hazardous hydrazine from the cytoplasm in the course of the anammox process. Acccording to present knowledge, this process is carried out exclusively by a group of bacteria that branches deeply within the Planctomycetes. Since these anammox planctomycetes are of industrial importance for wastewater treatment (Jetten et al., 1997) they are intensely studied.

Apart from that, our knowledge on planctomycetal physiologies is quite limited. Most of the strains so far isolated in pure culture have been from aquatic and aerobic habitats (Bauld and Staley, 1976; Franzmann and Skerman, 1984; Giovannoni et al., 1987b; Schlesner, 1994) and they are all obligate or facultative aerobic chemoheterotrophs that use 
carbohydrates as their major source of carbon. However, molecular methods like fluorescence in situ hybridization (FISH) and 16S ribosomal RNA (rRNA) gene sequencing as well as targeted cultivation efforts have revealed a much broader distribution of the Planctomycetes in the environment. They were detected in the water column and sediments of fresh water lakes (Neef et al., 1998; Miskin et al., 1999; Wang et al., 2002; Kalyuzhnaya et al., 2004, 2005a), hot springs (Giovannoni et al., 1987a), in the water column (DeLong et al., 1993; Vergin et al., 1998; Gade et al., 2004) as well as in shallow and deep sea sediments of marine systems (LlobetBrossa et al., 1998; Rusch et al., 2003; Inagaki et al., 2006; Musat et al., 2006) and in oxic and anoxic soils (Wang et al., 2002). Furthermore, planctomycetes have been detected in marine sponges (Fuerst et al., 1998, 1999; Pimentel-Elardo et al., 2003) and in the hepatopancreas of the crustacean Panaeus monodon (Fuerst et al., 1991, 1997), in freshwater (Crump et al., 1999), marine detritus particles (DeLong et al., 1993; Fuerst, 1995; Crump et al., 1999) and attached to diatoms (Morris et al., 2006).

At present, only a few Planctomycetes have been investigated by whole genome sequencing. So far, the genome of the marine planctomycete Rhodopirellula baltica $\mathrm{SH} 1^{\mathrm{T}}$ (formerly Pirellula sp. strain 1) is the only one that is completely closed (Glöckner et al., 2003). Besides, four largely completed planctomycete genomes are available. The anammox planctomycete 'Candidatus Kuenenia stuttgartiensis' was investigated by a metagenomic approach from a wastewater treatment plant enrichment culture (Strous et al., 2006). In addition, in collaboration with us, the Gordon and Betty Moore foundation has funded draft sequencing of the two marine planctomycetes Blastopirellula marina DSM $3645^{\mathrm{T}}$ (Schlesner et al., 2004) and Planctomyces maris DSM 8797 ${ }^{\mathrm{T}}$ (Bauld and Staley, 1976) and Ward and co-workers at The Institute for Genomic Research (TIGR) have generated an early draft of the genome of the freshwater isolate of Gemmata obscuriglobus UQM 2246 ${ }^{\mathrm{T}}$ (Franzmann and Skerman, 1984). A further draft of a Gemmata sp. genome, strain Wa-1, has been produced by Integrated Genomics (Chicago, IL, USA), that has recently been investigated with respect to a possible role of the ancestor of the Planctomycetes in the evoluton of the Eukarya (Staley et al., 2005).

Despite these genome sequencing projects, there is a need for further direct genomic and metagenomic studies of planctomycetes, since we know the group is diverse and its members are often difficult to culture. Hence, the true extent of the diversity of this group may only be accessible via metagenomic studies. To broaden our understanding about marine Planctomycetes, we present here comparative sequence analysis of six novel Planctomycete fosmids from two different upwelling systems and their comparison with all of the available Planctomycete genomic sequences (see Supplementary Figure 1 for sampling sites). Four of the fosmids were retrieved from the OMZ of the Benguela upwelling system at the Namibian coast, and two originate from $200 \mathrm{~m}$ depth off the coast of Oregon (Stein et al., 1996; Vergin et al., 1998). At the same time, this is the first study that includes results from our annotation of the almost complete genomes of Blastopirellula marina DSM $3645^{\mathrm{T}}$ and Planctomyces maris DSM $8797^{\mathrm{T}}$. With these new draft genomes, we now have genomic sequences from four of the six accepted planctomycete genera. In this study we investigated planctomycete-specific genes as well as metabolic genes like sulfatases and those involved in the C1 metabolism.

\section{Materials and methods}

Metagenome sampling

In this study, two metagenome libraries were investigated: the first was constructed from picoplankton samples taken during a cruise in the eastern North Pacific at $200 \mathrm{~m}$ depth off the Oregon coast (44.012 N, 124.955 W) in August 1992 as described in Stein et al. (1996). The second was constructed from Namibian shelf water sampled during an R/V Meteor cruise in March/April 2003 at station M202 (22.64 ${ }^{\circ} \mathrm{S}$ and $14.30^{\circ} \mathrm{E}$ ) (Supplementary Figure 1). This sample was taken from $52 \mathrm{~m}$ depth, where $2 \mu \mathrm{M}$ nitrite, $4.6 \mu \mathrm{M}$ nitrate, and oxygen and ammonium concentration below the detection limit were measured (Kuypers et al., 2005). About 5001 seawater were brought onto pre-combusted (at $450^{\circ} \mathrm{C}$ ) fiber glass filters (GFF; nominal pore size, $0.7 \mu \mathrm{m}$ ) and stored at $-80^{\circ} \mathrm{C}$ until further processing.

\section{Fosmid library construction}

The metagenome library from the North Pacific was constructed as described in Stein et al. (1996). The library from the Namibian upwelling system was constructed as follows: high molecular weight DNA was extracted according to the protocol from Zhou et al. (1996). Cell saver tips (that is, tips with an extra large opening) were taken for DNA extraction to avoid shearing the DNA. To avoid DNA loss due to DNA binding to the filter glass material, cells were washed off the filters with the extraction buffer without proteinase $\mathrm{K}$ and SDS before the extraction procedure.

After DNA extraction, the RNA was digested with RNAse A in $0.5 \times$ TE (final RNAse A concentration: $100 \mu \mathrm{g} / \mathrm{ml}$ ) for $1 \mathrm{~h}$ at room temperature. Subsequently, the RNAse was inactivated at $60^{\circ} \mathrm{C}$ for $10 \mathrm{~min}$, an equal amount of chloroform/isoamyl alcohol mixture was added and the supernatant was precipitated with $1 / 10$ volume of NaOAc and 0.6 volume of isopropanol (incubation for $1 \mathrm{~h}$ at room temperature and centrifugation). The DNA was stored in $0.5 \times \mathrm{TE}$ and the ends of the DNA were 
filled blunt-ended according to the protocol of the Copy Control Fosmid Library Production Kit (EPICENTRE Biotechnologies, Madison, WI, USA).

We selected DNA of $30-45 \mathrm{~kb}$ for subsequent ligation into the vector via application of pulsedfield gel electrophoresis (PFGE) (1\% LMT agarose; in $0.5 \times$ TBE; program of PFGE: run time $12 \mathrm{~h}$ at $14^{\circ} \mathrm{C}$; angle of $120^{\circ} ; 6 \mathrm{~V} / \mathrm{cm}$; initial switch time $1 \mathrm{~s}$, final switch time $10 \mathrm{~s}$; afterwards for $1.3 \mathrm{~h}$ initial and final switch time $2 \mathrm{~min})$. After cutting the band of the desired size $(30-45 \mathrm{~kb})$, we equilibrated the DNA three times in $1 \times \mathrm{TE}$ (each $30 \mathrm{~min}$ ) and digested the agarose with $\beta$-agarase $(1000 \mathrm{U} / \mathrm{ml} ; 1 \mu \mathrm{l} / 100 \mathrm{mg}$ agarose gel). The DNA was concentrated and washed with $1 \times \mathrm{TE}$ using a Microcon tube (Millipore, Billerica, MA, USA) and subsequently eluted in PCR water.

The DNA was ligated into CopyControl pCC1FOS vectors (EPICENTRE Biotechnologies, Madison) at $4^{\circ} \mathrm{C}$ for 2 days. The vectors were packaged into the MaxPlax lambda phage (EPICENTRE Biotechnologies). Escherichia coli cells of the strain EPI300-T1R (EPICENTRE Biotechnologies) were infected with the phages upon reaching an OD of $0.8-1.0$ and plated onto LB-chloramphenicol plates $(12.5 \mu \mathrm{g} / \mathrm{ml})$. About 10000 grown colonies were transferred into LB medium containing chloramphenicol $(12.5 \mu \mathrm{g} /$ $\mathrm{ml}), \mathrm{MgSO}_{4}(10 \mathrm{~mm})$, and glycerol $(8 \%)$ and stored at $-80^{\circ} \mathrm{C}$. Additionally, clones were pooled according to the row-column-plate scheme (Asakawa et al., 1997) and incubated overnight at $37^{\circ} \mathrm{C}$. The DNA was subsequently extracted using the 96-well Montage plasmid preparation kit (Millipore) and stored at $-80^{\circ} \mathrm{C}$.

\section{Fosmid library screening}

The Oregon coast metagenome library was screened for fosmids containing planctomycete 16S rRNA genes as described in Vergin et al. (1998). Four planctomycete fosmids were detected in 3552 screened clones and from those four, fosmids $5 \mathrm{H} 12$ and 6N14 were provided by courtesy of Edward DeLong.

The fosmid library from the Namibian upwelling system was screened by PCR with the planctomycete-targeting primer Pla46F (Neef et al., 1998) and the universal primer 1392R (Pace et al., 1986). In view of the pooling scheme, we could trace back the positive PCR products to single clones of the fosmid library. The 16S rRNA genes were sequenced and their phylogeny was reconstructed using the ARB software (Ludwig et al., 2004) in conjunction with the SILVA database (www.arb-silva.de). In total, 10000 clones were screened and 12 clones with planctomycete DNA were obtained.

\section{Insert size determination}

The respective clones were induced for high copy number according to the instructions of the Copy-
Control Fosmid Library Production Kit (EPICENTRE Biotechnologies). Fosmids were then isolated following the QIAprep Spin Miniprep Protocol (Qiagen, Hilden, Germany). Aliquots of $25 \mu \mathrm{l}$ of fosmid DNA were digested with NotI $(10000 \mathrm{U} / \mu \mathrm{l})$, and the digestion was stopped by heating at $65^{\circ} \mathrm{C}$ for $10 \mathrm{~min}$ and quickly placed on ice. The sizes of the resulting fragments were checked by PFGE $(0.5 \times \mathrm{TBE}, 1 \%$ pulsed field certified agarose (BioRad, Hercules, CA, USA), initial switch time $5 \mathrm{~s}$, final switch time $15 \mathrm{~s}, 6 \mathrm{~V} / \mathrm{cm}$, angle: $120^{\circ}$; run time: $\left.17 \mathrm{~h}, 14^{\circ} \mathrm{C}\right)$.

\section{Fosmid sequencing}

Clones 5H12 and 6N14 from the Oregon coast planctomycete fosmids were selected and sequenced at Integrated Genomics (Jena, Germany). From the 12 planctomycete fosmids from the Namibian metagenome library, four fosmids (3FN, $6 \mathrm{FN}, 8 \mathrm{FN}$ and $13 \mathrm{FN}$ ) were chosen for sequencing based on the phylogenetic position of the planctomycete 16S rRNA gene and the determined insert size. For that purpose, large amounts of fosmid DNA were extracted after induction of the fosmids with the Qiagen Large-Construct Kit (Qiagen). Shotgun sequencing of the fosmids was conducted by AGOWA (Berlin, Germany) resulting in a single contig each.

\section{Gene prediction and annotation}

Gene prediction was adapted for each sequence individually. For the rather short fosmid sequences, all open reading frames (ORFs) exceeding 90 nucleotides were taken into account for annotation. Overpredicted genes were sorted out during manual annotation.

Preliminary sequence data from Gemmata obscuriglobus UQM $2246^{\mathrm{T}}$ were obtained from The Institute for Genomic Research (TIGR) through the website at http://www.tigr.org and GLIMMER v2 (Delcher et al., 1999) was used for the gene prediction of the G. obscuriglobus UQM $2246^{\mathrm{T}} \mathrm{draft}$ genome. For the published genomes of R. baltica SH $1^{\mathrm{T}}$ and 'Candidatus K. stuttgartiensis', the original gene prediction was retained. For the two planctomycete draft genomes sequenced by the Moore foundation, the supplied gene prediction was evaluated against an in-house gene prediction pipeline (MORFind, unpublished) that post-processes the outputs of CRITICA (Badger and Olsen, 1999), GLIMMER v2 (Delcher et al., 1999) and Zcurve (Guo et al., 2003). In the case of $P$. maris DSM $8797^{\mathrm{T}}$ the original gene prediction was kept since it could not be further enhanced, but for B. marina DSM $3645^{\mathrm{T}}$, a more accurate gene prediction could be generated by additional cross-comparisons with the other planctomycete genomes.

Annotation was accomplished with the GenDB v2 system (Meyer et al., 2003), using various bioinfor- 
matic tools for each predicted gene ranging from similarity searches against sequence databases (NCBI nr, NCBI nt, SwissProt) and protein family databases (Pfam, Prosite, InterPro, COG) to signal peptide- (SignalP v2.0; Nielson et al., 1997) and transmembrane helix predictions (TMHMM v2.0 Krogh et al., 2001). From these predictions, an automatic annotation was generated using the fuzzy logic-based autoannotation tool MicHanThi (Quast, 2006). High-quality annotations were generated by manual revision of each gene's annotation for the fosmids and the draft genome of $B$. marina DSM $3645^{\mathrm{T}}$.

\section{Transcriptome analysis}

$R$. baltica $\mathrm{SH} 1^{\mathrm{T}}$ cells were grown as batch cultures with glucose as carbon and ammonium chloride as nitrogen source on a rotary shaker (100 r.p.m.) at $28^{\circ} \mathrm{C}$ in the dark (Rabus et al., 2002). The medium used was a modified M13a medium (Schlesner, 1994) with the original complex substrates (yeast extract, peptone) replaced by $10 \mathrm{~mm}$ glucose and $1 \mathrm{mM}$ ammonium chloride. Cultures were harvested by centrifugation (Beckman CoulterTM AvantiTM J-20XP, JA10 Rotor, 20 min, 6000 r.p.m., $4^{\circ} \mathrm{C}$ ), resuspended in $10 \times$ TAE buffer and then re-centrifuged to cell pellets that were shock-frozen in liquid nitrogen and stored at $-80^{\circ} \mathrm{C}$.

The set of oligonucleotides corresponding to the whole genome of $R$. baltica SH $1^{\mathrm{T}}$ (Pirellula AROS Version 1.0) was purchased from Operon (Cologne, Germany) and diluted to $20 \mu \mathrm{M}$ concentration in Micro Spotting Solution Plus spotting buffer (Telechem, Sunnyvale, CA, USA). Spotting was done in three replicates onto GAPS II aminosilane slides (Corning, Schiphol-Rijk, Netherlands) using a SpotArray 24 spotting device (Perkin Elmer, Wellesley, MA, USA). Post-processing and blocking of the slides were done according to the manufacturer's instructions. For hybridization at least $2 \mu \mathrm{g}$ of Alexa 546 dye-labeled and $2 \mu \mathrm{g}$ of Alexa 647 dye-labeled total cDNA were used. Blocking, hybridization and washing were carried out in an automated hybridization station HS400 (Tecan, Crailsheim, Germany).

Slides were scanned at a resolution of $5 \mu \mathrm{m}$ using a ScanArray Express Microarray scanner (Perkin Elmer). The image analysis software provided with this scanner was used for automatic spot detection and signal quantification. Raw data were automatically processed using the microarray data analysis software tool MADA (http://www.mpi-bremen.de/ en/mada).

\section{Sequence availability}

Fosmid sequences are available under the following accession numbers from GenBank: EF591884 (5H12), EF591885 (6N14), EF591886 (3FN), EF591887 (6FN), EF591888 (8FN), EF591889 (13FN). The almost com- plete genomes of B. marina DSM $3645^{\mathrm{T}}$ and $P$. maris DSM $8798^{\mathrm{T}}$ have been sequenced in the framework of the Microbial Genome Sequencing Project of the Gordon and Betty Moore foundation (http:// www.moore.org/microgenome/). Gene predictions and annotations of these sequences are available on request.

\section{Comparative genomics}

All comparative analyses were performed using custom-made JAVA-based frameworks that operate directly on GenDB MySQL databases and allow working with multiple of these databases at once (details about authorships and code are available on request).

Planctomycete-specific genes were identified by searching all genes of the investigated planctomycete sequences, with BLAST against an in-house database (genomesDB). This database was constructed from the proteome FASTA files of all fully sequenced bacterial and archaeal genomes plus some almost complete genome drafts (440 on April 2007 ), in which each protein was tagged by a unique numerical identifier in the header that encodes the species, the chromosome and the gene itself. Two approaches were taken to determine whether or not a gene was planctomycete-specific. In the first, two E-value thresholds were used as criteria to separate planctomycete and non-planctomycete hits: an upper threshold (E-6) was used, above which all BLAST hits were regarded as insignificant noise. Hence, in order for a gene to be planctomycetespecific, no non-planctomycete hits were allowed below this boundary. In addition, a lower threshold (E-15) was used, below which BLAST hits were regarded as targeting the same gene. Only those genes having planctomycete hits below this boundary were considered. Genes complying with both of these criteria were regarded as planctomycetespecific. In the second approach, only those genes were regarded as planctomycete-specific where all BLAST hits better than E-10 exclusively targeted Planctomycetes. In both cases, self-matching BLAST hits and hits to intragenomic homologs were filtered from the analysis.

Besides planctomycete-specific genes, we also searched for orphaned, genome-specific genes, which are genes without known homologs in any other genome. A gene was regarded as orphaned, if it had no BLAST hit below E-7 in the non-redundant NCBI $\mathrm{nr}$ or the genomesDB databases.

Codon usage analysis

Codon usage analysis was carried out with CIAJava (Carbone et al., 2003) and codonw (Peden, 1999). CAIJava was used for each genome with the full set of predicted genes and with the standard 15 iterations. Codonw was used for each of the genomes with a high-quality training set of genes 
for the initial correspondence analysis that was generated by filtering all genes smaller than $300 \mathrm{bp}$ as well as genes coding for hypothetical proteins, phage proteins, transposases and integrases. Thereafter, the extracted codon usage characteristics were used to analyze the codon usage of all genes.

\section{Results}

Characterization and phylogenetic assignment of the obtained fosmid sequences

The size of the fosmid inserts ranged from $34.6 \mathrm{~kb}$ (fosmid 8FN) to $42.5 \mathrm{~kb}$ (fosmid 6N14) (Table 1) with a G+C-content from $\sim 48 \%$ to $\sim 60 \%$, which reflects the $\mathrm{G}+\mathrm{C}$-content variation of the Planctomycete genomes (Table 2). The number of ORFs per fosmid insert ranged from 27 to 33 .

Based on 16S rRNA analysis, phylogenetic assignments were made for the fosmid insert sequences obtained from the Namibian (3FN, 6FN, 8FN, 13FN) and Oregon (5H12, 6N14) coasts. A phylogenetic reconstruction based on tree calculation with neighbor joining, maximum likelihood and maximum parsimony algorithms (without and with 50\% position variability filter) is shown in Figure 1.

Fosmid insert 13FN exhibited highest 16S rRNA sequence similarity to an uncultured planctomycete sequence from Lake Bonney, a permanently icecovered lake in Antarctica (DQ015853, 94.9\% identity). Its closest cultivated planctomycete was Planctomyces maris DSM $8797^{\mathrm{T}}$ (87.5\% identity). Likewise, the $16 \mathrm{~S}$ rRNA of $P$. maris DSM $8797^{\mathrm{T}}$ was also the closest cultured relative to fosmid insert 3FN (88.7\% identity), which however, was most similar to a planctomycete sequence from a hydrocarbon-contaminated soil (DQ298013, 89.2\%). Fosmid insert $6 \mathrm{FN}$ had a very high similarity to the $16 \mathrm{~S}$ rRNA sequence from an uncultured marine snowassociated planctomycete (L10942, 99.0\% identity). The sequence identity to the next cultured relatives, two Blastopirellula marina DSM $3645^{\mathrm{T}}$-related strains (AJ231179 and AJ231180), was considerably lower (87.5\% identity). Clone 8FN exhibited highest sequence identity to a sequence originating from a deep-sea mud volcano in the eastern Mediterranean (AY592598, 92\% identity). The next cultured relative was a Blastopirellula-related planctomycete isolated from the postlarvae of the giant tiger prawn (Penaeus monodon) (X86391, 89.9\% identity).

Fosmid 6N14 had highest sequence identity with an uncultured planctomycete from heavy metalcontaminated surface sediments in the North Sea (98.2\%, DQ351810) and is related to Rhodopirellula baltica SH $1^{\mathrm{T}}$ (95.7\% identity). Clone $5 \mathrm{H} 12$ grouped, together with $8 \mathrm{FN}$ and $6 \mathrm{FN}$, within a cluster of

Table 1 Characterization of fosmids: insert size, G+C-content, number of ORFs and sampling location

\begin{tabular}{|c|c|c|c|c|c|c|}
\hline & $3 F N$ & $6 F N$ & $8 F N$ & $13 F N$ & $5 H 12$ & $6 N 14$ \\
\hline Fosmid insert size $(\mathrm{kb})$ & 37.0 & 40.7 & 34.6 & 36.7 & 41.0 & 42.5 \\
\hline $\mathrm{G}+\mathrm{C}$-content $(\%)$ & 59.7 & 47.8 & 50.8 & 55.0 & 51.0 & 52.4 \\
\hline Number of ORFs after manual annotation & 27 & 28 & 33 & 31 & 31 & 32 \\
\hline Sampling location & \multicolumn{4}{|c|}{$\begin{array}{l}\text { Namibian upwelling system } \\
\text { (Kuypers et al., 2005) }\end{array}$} & \multicolumn{2}{|c|}{$\begin{array}{l}\text { Oregon upwelling system } \\
\text { (Stein et al., 1996) }\end{array}$} \\
\hline
\end{tabular}

Table 2 Characterization of the planctomycete genomes: genome size, G+C-content, number of sulfatases, number of orphan and number of Planctomycete group-specific genes (GSG) and their domains of unknown functions (Pfam Accession numbers are indicated in parentheses)

\begin{tabular}{|c|c|c|c|c|c|}
\hline & R. baltica & P. maris & B. marina & G. obscuriglobus & K. stuttgartiensis \\
\hline Genome size & $7145 \mathrm{~kb}$ & $7775 \mathrm{~kb}$ & $6655 \mathrm{~kb}$ & $9106 \mathrm{~kb}$ & $4218 \mathrm{~kb}$ \\
\hline $\mathrm{G}+\mathrm{C}$ content $(\%)$ & 55.4 & 51.2 & 57.2 & 67.1 & 40.8 \\
\hline No. of predicted genes & 7325 & 6531 & 5600 & $(13024)^{a}$ & 4710 \\
\hline \multirow[t]{2}{*}{ No. of orphan genes ${ }^{b}$} & 2897 & 1559 & 1088 & $(5989)^{a}$ & 1364 \\
\hline & $(39.5 \%)$ & $(24.5 \%)$ & $(19.4 \%)$ & $(46.0 \%)^{\mathrm{a}}$ & $(29.0 \%)$ \\
\hline No. of GSG w/o KS & 125 & 200 & 249 & 154 & - \\
\hline No. of GSG with $\mathrm{KS}^{\mathrm{c}}$ & 3 & 3 & 3 & 3 & 2 \\
\hline No. of sulfatases ${ }^{\mathrm{d}}$ & $109(15.3 / \mathrm{Mb})$ & $83(10.7 / \mathrm{Mb})$ & $41(6.2 / \mathrm{Mb})$ & $12(1.3 / \mathrm{Mb})$ & $3(0.7 / \mathrm{Mb})$ \\
\hline No. of Pfam profile DUF1501 ${ }^{\mathrm{d}}$ (PF07394) & 41 & 94 & 31 & 61 & 0 \\
\hline No. of Pfam profile PSCyt2/DUF1549 ${ }^{\mathrm{d}}$ (PF07583) & 41 & 68 & 32 & 43 & 0 \\
\hline No. of Pfam profile PSD1/DUF1553 ${ }^{\mathrm{d}}$ (PF07587) & 41 & 68 & 32 & 43 & 0 \\
\hline No. of Pfam profile PSCyt1 (CytC) ${ }^{\mathrm{d}}$ (PF07635) & 53 & 54 & 32 & 27 & 0 \\
\hline No. of Pfam profile SBP_bac_10/DUF1559d (PF07596) & 74 & 134 & 197 & 125 & 0 \\
\hline No. of Pfam profile DUF1551 ${ }^{\mathrm{d}}$ (PF07585) & 6 & 2 & 1 & 7 & 0 \\
\hline
\end{tabular}

${ }^{a}$ Overprediction by Glimmer 2.

${ }^{\mathrm{b}} \mathrm{E}$ value E-7 or better.

'Upper boundary: E-15, lower boundary: E-6.

${ }^{\mathrm{d}} \mathrm{E}$ value E-5 or better. 


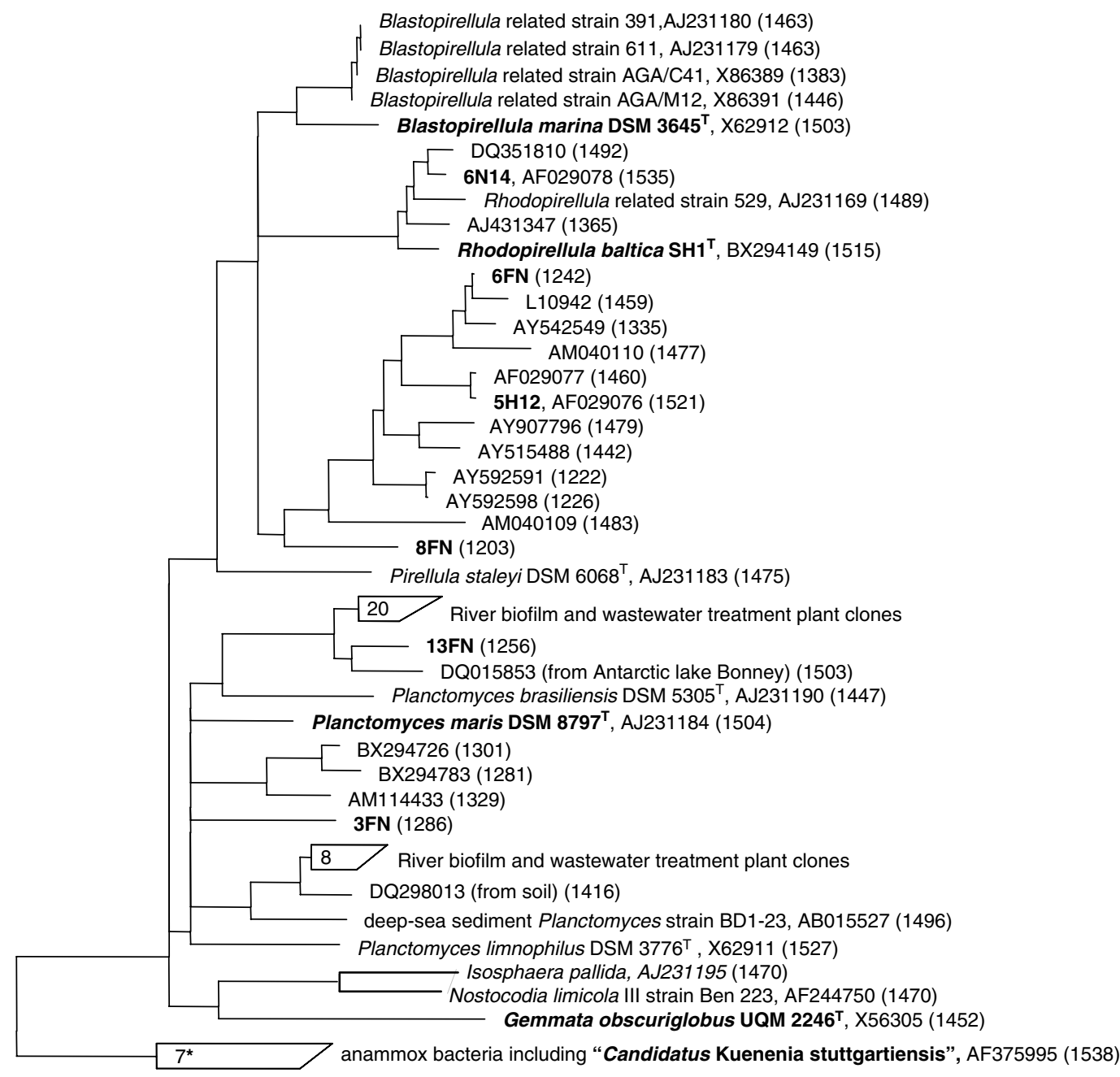

$10 \%$

Figure 1 Phylogenetic tree based on 16S rRNA sequences showing the phylogenetic affiliation of fosmids and genomes used in this study. The consensus tree was constructed after tree calculation with neighbor joining, maximum parsimony and maximum likelihood algorithms with and without $50 \%$ position variability filters. Lengths of the sequences are indicated in parentheses. Anammox bacteria (group indicated by an asterisk comprising of 'Cand. K. stuttgartiensis', 'Cand. B. anammoxidans', 'Cand. B. fulgida', 'Cand A. propionicus', 'Cand. J. asiatica', 'Cand. S. sorokinii' and 'Cand. S. brodae') were used as outgroup. The bar represents $10 \%$ estimated sequence divergence.

uncultured planctomycetes and showed highest sequence identity to a fosmid from the same metagenome library (uncultured Pirellula clone 6013, AF029077, 99.7\%, identity, (Vergin et al., 1998)). The closest cultured representatives were a group of isolates retrieved from the postlarvae of Penaeus monodon (for example, X86389, 88.9\% identity).

Genes involved in C1 metabolism

Previous studies have shown that the genomes of $R$. baltica SH $1^{\mathrm{T}}$ and G. obscuriglobus UQM $2246^{\mathrm{T}}$ both contain genes involved in tetrahydromethanopterin-( $\left.\mathrm{H}_{4} \mathrm{MPT}\right)$-linked C1-compound conversions (Supplementary Figure 2) and the biosynthesis of the associated essential cofactor methanopterin
(Glöckner et al., 2003; Bauer et al., 2004; Chistoserdova et al., 2004).

In addition to the already described C1 metabolism genes in $R$. baltica $\mathrm{SH} 1^{\mathrm{T}}$ and $G$. obscuriglobus UQM $2246^{\mathrm{T}}$, we could identify homologs to all known $\mathrm{C} 1$ genes in the draft genome of $B$. marina DSM $3645^{\mathrm{T}}$ and, with the exception of ORF21, also in the P. maris DSM $9787^{\mathrm{T}}$ draft. In contrast, none of these genes was found in the draft genome of Candidatus K. stuttgartiensis (Table 3 and Figure 2).

R. baltica SH $1^{\mathrm{T}}$ and $G$. obscuriglobus UQM $2246^{\mathrm{T}}$ have two copies of the formaldehyde-activating enzyme gene (fae 1 and $f a e 2-31 \%$ and $28 \%$ amino acid (aa) identity, respectively). We also found two fae copies in P. maris DSM $8797^{\mathrm{T}}$ (38\% aa identity) but only one in $B$. marina DSM $3645^{\mathrm{T}}$. Within $R$. baltica $\mathrm{SH} 1^{\mathrm{T}}$, fae1 is characterized by a rigidly 
Table 3 Presence and absence of archaea-like and bacteria-like $\mathrm{H}_{4}$ MPT-dependent genes in the studied Planctomycete genomes and fosmids

\begin{tabular}{|c|c|c|c|c|c|c|c|c|c|c|c|}
\hline Gene & R.b. ${ }^{\mathrm{a}}$ & G.o. ${ }^{\mathrm{a}}$ & B.m. ${ }^{\mathrm{a}}$ & P.m. ${ }^{\mathrm{a}}$ & K.s. ${ }^{\mathrm{a}}$ & $3 F N$ & $6 F N$ & $8 F N$ & $13 F N$ & $5 H 12$ & $6 N 14$ \\
\hline ORF5 & + & + & + & + & - & - & - & - & - & - & - \\
\hline ORF7 & + & + & + & + & - & - & - & - & - & - & - \\
\hline ORF9 & + & + & + & + & - & - & - & - & - & - & - \\
\hline ORF17 & + & + & + & + & - & - & - & - & - & - & - \\
\hline ORF19 & + & + & + & + & - & - & - & + & - & - & - \\
\hline ORF20 & + & + & + & + & - & - & - & + & - & - & - \\
\hline ORF21 & + & + & + & - & - & - & - & - & - & - & - \\
\hline ORF22 & + & + & + & + & - & - & - & - & - & - & - \\
\hline$O R F Y$ & + & + & + & + & - & - & - & - & - & - & - \\
\hline fae 1 & + & + & + & + & - & - & - & - & - & - & - \\
\hline fae 2 & + & + & - & + & - & - & - & - & - & - & - \\
\hline$f t r^{b}$ & + & + & + & + & - & - & - & - & - & - & - \\
\hline Mch & + & + & + & + & - & - & - & - & - & - & - \\
\hline$m p t G$ & + & + & + & + & - & - & - & + & - & - & - \\
\hline$m t d C$ & + & + & + & + & - & - & - & - & - & - & - \\
\hline$f m d A B C^{\mathrm{b}}$ & $+/-1+$ & $+/+/+$ & $+/+/+$ & $+/+/+$ & - & - & $-1-1+$ & - & - & - & - \\
\hline ORF1 & + & + & + & + & - & - & - & - & - & - & - \\
\hline$p a b A B$ & + & - & + & + & - & - & - & + & - & - & - \\
\hline$p t S$ & + & + & + & + & - & - & - & - & - & - & - \\
\hline
\end{tabular}

${ }^{\mathrm{a}}$ R.b.: Rhodopirellula baltica SH 1 ${ }^{\mathrm{T}}$; G.o.: Gemmata obscuriglobus UQM 2246 ${ }^{\mathrm{T}}$; B.m.: Blastopirellula marina DSM $3645^{\mathrm{T}}$ and P.m.: Planctomyces maris $8797^{\mathrm{T}}$.

${ }^{b}$ Ftr together with the three subunits of Fmd forms the formyltransferase/hydrolase complex (fhc).

optimized codon usage indicating a high level of expression (Bauer et al., 2004). This is also the case within B. marina DSM $3645^{\mathrm{T}}$, whose fae1 gene has the third highest codon adaptation index (CAI) of all of its genes, but not for the P. maris DSM $8797^{\mathrm{T}}$ fae gene. In all four genomes, fae1 is located upstream of a gene coding for the recently discovered methylene tetrahydromethanopterin gene $\operatorname{mtdC}$ (Vorholt et al., 2005). In $R$. baltica SH $1^{\mathrm{T}}, B$. marina DSM $3645^{\mathrm{T}}$ and P. maris DSM $8797^{\mathrm{T}}$, fae1 and mtdC are located adjacent to $O R F Y$, a gene with as yet unknown function. Likewise, mch (encoding methenyl $\mathrm{H}_{4} \mathrm{MPT}$ cyclohydrolase) is located directly upstream of ORF5 (most likely involved in the biosynthesis of $\mathrm{H}_{4} \mathrm{MPT}$ ) in all four Planctomycete genomes. Clustering of formyl- $\mathrm{H}_{4} \mathrm{MPT}$-dehydrogenase subunits $\mathrm{A}$ and $\mathrm{C}(\mathrm{fm}(\mathrm{w}) d A / C)$ with formylmethanofuran: $\mathrm{H}_{4} \mathrm{MPT}$-formyltransferase $(\mathrm{ftr}$ ) could be observed in $R$. baltica SH $1^{\mathrm{T}}$, while in $G$. obscuriglobus UQM $2246^{\mathrm{T}}$ the $\mathrm{fm}(w) d C$ and ftr genes are co-located. Within B. marina DSM $3645^{\mathrm{T}}$ and $P$. maris DSM $8797^{\mathrm{T}}$, the $\mathrm{ftr}$ gene was not located adjacent to any of the $f m(w) d$ genes. In all four Planctomycete genomes, ORF19 was found to be linked to mptG. ORF19 is involved in $\mathrm{H}_{4} \mathrm{MPT}$ biosynthesis (Chistoserdova et al., 2005), while $m p t G$ codes for $\beta$-RFAP synthase, an enzyme that catalyzes the first reaction distinguishing the methanopterin biosynthesis pathway from that of folate biosynthesis (Scott and Rasche, 2002; Chistoserdova et al., 2004).

Clustering of ORF9 with ORF21 was observed in three genomes: $R$. baltica $\mathrm{SH} 1^{\mathrm{T}}, B$. marina DSM $3645^{\mathrm{T}}$ and $G$. obscuriglobus UQM $2246^{\mathrm{T}}$. These two genes are also involved in $\mathrm{H}_{4} \mathrm{MPT}$ biosynthesis
(Chistoserdova et al., 2005). Further co-localizations cover ORF9 and ORF1 in B. marina DSM $3645^{\mathrm{T}}$ and P. maris DSM $8797^{\mathrm{T}}$, and ORF7 and pts in B. marina DSM $3645^{\mathrm{T}}, P$. maris DSM $8797^{\mathrm{T}}$ and G. obscuriglobus UQM $2246^{\mathrm{T}}$.

Genes involved in the $\mathrm{H}_{4}$ MPT-linked C1 metabolism were also found on two of the four fosmids from the Namibian OMZ (Table 3 and Figure 2). Fosmid 6FN harbors an instance of $f m d C$ plus the gene $m o b A$ that encodes the molybdopterin-guanine dinucleotide biosynthesis protein A. Fosmid 8FN contains a larger C1 module comprising ORF20pabB-pabA-ORF19-mptG. This complete module could also be identified in B. marina DSM $3645^{\mathrm{T}}$, while $P$. maris DSM $8797^{\mathrm{T}}$ contained these genes in two separate clusters of ORF20-pabB-pabA and ORF19-mptG. $R$. baltica $\mathrm{SH} 1^{\mathrm{T}}$ has the cluster pabA-ORF19-mptG, while ORF20 is isolated and pabB is co-localized with the C1 genes ORF5 and mch. In G. obsucriglobus UQM $2246^{\mathrm{T}}$ finally, only the genes ORF19-mptG from this cluster could be found. ORF19 and ORF20 are also co-localized in the methylotroph $M$. extorquens AM1 and have been shown to be essential for the biosynthesis of $\mathrm{H}_{4} \mathrm{MPT}$ (Chistoserdova et al., 2005). MptG encodes a GHMP family kinase, and $p a b A$ and $p a b B$ the p-aminobenzoate synthase glutamine amidotransferase component II and the p-aminobenzoate synthase component I, respectively (Kalyuzhnaya et al., 2005b).

Expression profiling on glucose-grown $R$. baltica $\mathrm{SH} 1^{\mathrm{T}}$ cells revealed that even in the absence of $\mathrm{C} 1$ compounds seven of the respective genes are expressed, namely ORF21, fae, $f m(w) d A$, $f m(w) d C$, ORF7, $m t d C$ and ORF1. 


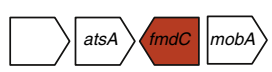

Contig 3
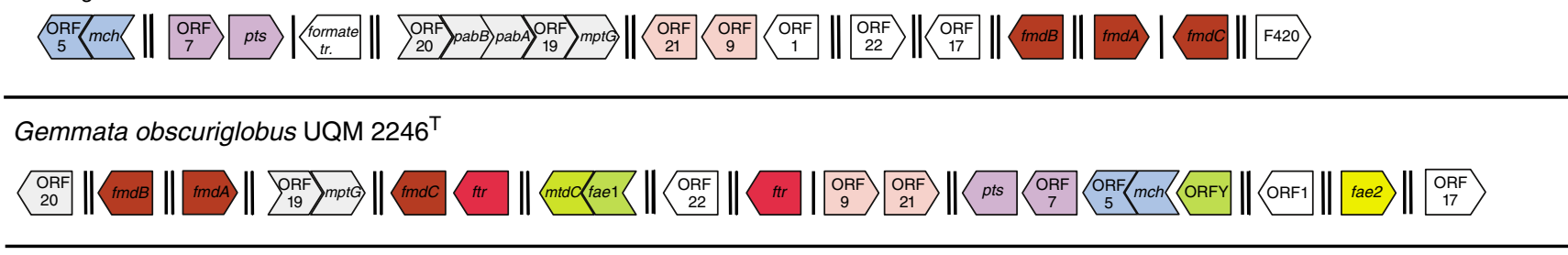

Planctomyces maris $8797^{\top}$

Contig 1101493009189

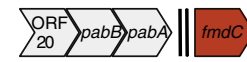

Contig 1101493009195

\section{(1)}

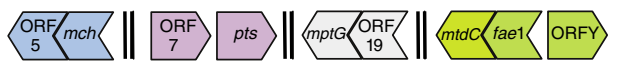

Contig 1101493009191

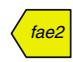

Contig 1101493009199

$\left.\left.\begin{array}{c}\text { ORF } \\ 1\end{array}\right\rangle \begin{array}{c}\text { ORF } \\ 9\end{array}\right\rangle$ ftr $\|<$ fmdA $\left\|<\begin{array}{c}\text { ORF } \\ 22\end{array}\right\|<$ fmaB

Rhodopirellula baltica $\mathrm{SH} 1^{\top}$

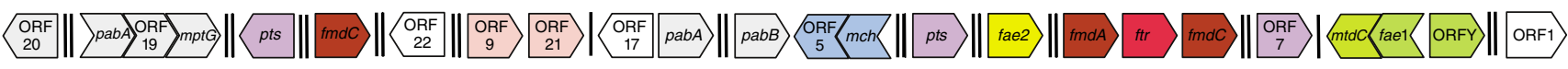

Methylobacterium extorquens AM1

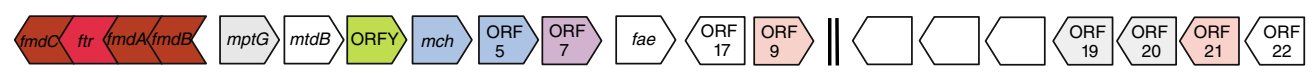

Figure 2 Genomic arrangement of genes involved in $\mathrm{H}_{4} \mathrm{MPT}$-dependent C1-transfer. Comparison of fosmids $6 \mathrm{FN}$ and 8FN from the Namibian upwelling system, genomes of the planctomycetes Blastopirellula marina DSM $3645^{\mathrm{T}}$, Gemmata obscuriglobus UQM $2246^{\mathrm{T}}$, Planctomyces maris $8797^{\mathrm{T}}$, Rhodopirellula baltica SH $1^{\mathrm{T}}$ and the methylotrophic Alphaproteobacterium Methylobacterium extorquens AM1. Inserted arrows state that ORFs are organized in operons. A single line separating arrows indicate that ORFs are separated by at most 50 ORFs; double lines represent a separation by $>50$ ORFs.

Planctomycete-specific genes

Having multiple Planctomycete genomes at hand opens the possibility for the identification of planctomycete-specific genes. Among these, the ones that are present in all five planctomycetes investigated are of particular interest, since they define a Planctomycete and hence must include the genes coding for their unique cellular characteristics and planctomycete-specific metabolic traits.

To our surprise, only 2-3 genes were found when searching for such genes. A closer investigation revealed that 'Candidatus $\mathrm{K}$. stuttgartiensis' was almost devoid of genes that occur in all other planctomycetes. If left out, the remaining four planctomycetes had between 125 and 249 genes that were specific for them (Table 2). A considerable proportion of these planctomycete-specific genes were made up by large paralogous gene families that were defined by the occurrence of one or more specific domains of as yet unknown function (DUF), in particular the DUF1501, PSD1 (DUF1553) and DUF1559 as well as the planctomycete-specific cytochrome $c$-like domains PSCyt1 and PSCyt2 (DUF1549). These domains were previously identified as organism-specific domains within $R$. baltica SH $1^{\mathrm{T}}$ (Studholme et al., 2004). Frequently, the planctomycete-specific genes appeared in tandems. The most prominent of these tandems consisted of a gene carrying DUF1501 and a gene containing DUF1549 plus DUF1553 and sometimes an additional planctomycete-specific cytochrome $c$ domain (Table 4). A remarkable high proportion of these genes had signal peptide predictions, especially the DUF1549/DUF1553 genes.

When the five planctomycete genomic sequences were searched for planctomycete-specific genes 
Table 4 Statistical analysis of DUFs ${ }^{\mathrm{a}}$ in tandem structures on the planctomycete genomes

\begin{tabular}{|c|c|c|c|c|c|}
\hline & R. baltica & P. maris & B. marina & G. obscuriglobus & K. stuttgartiensis \\
\hline $\begin{array}{l}\text { Number of tandem occurrences (search started } \\
\text { with DUF1501) }\end{array}$ & 39 & ND & 30 & 22 & 0 \\
\hline $\begin{array}{l}\text { Percentage of genes with DUF1501 that appear in } \\
\text { tandem }\end{array}$ & $95.1 \%$ & ND & $96.8 \%$ & $36.1 \%$ & 0 \\
\hline $\begin{array}{l}\text { Number of genes containing DUF1549 and } \\
\text { DUF } 1553 \text { from tandems having signal peptides }\end{array}$ & 21 & ND & 21 & 12 & 0 \\
\hline $\begin{array}{l}\text { Percentage of secreted genes with DUF1549 and } \\
\text { DUF1553 from tandems }\end{array}$ & $53.8 \%$ & ND & $70.0 \%$ & $54.5 \%$ & 0 \\
\hline $\begin{array}{l}\text { Number of genes with DUF1549 and DUF1553 } \\
\text { from tandems which also contain CytC domain }\end{array}$ & 28 & ND & 18 & 11 & 0 \\
\hline $\begin{array}{l}\text { Percentage of genes with DUF1549, DUF1553 and } \\
\text { CytC domain present in tandems }\end{array}$ & $71.8 \%$ & ND & $60.0 \%$ & $50.0 \%$ & 0 \\
\hline
\end{tabular}

DUF1553 = PSD1; DUF1549 = PSCyt2.

${ }^{\mathrm{a} D U F}$ : domain of unknown function.

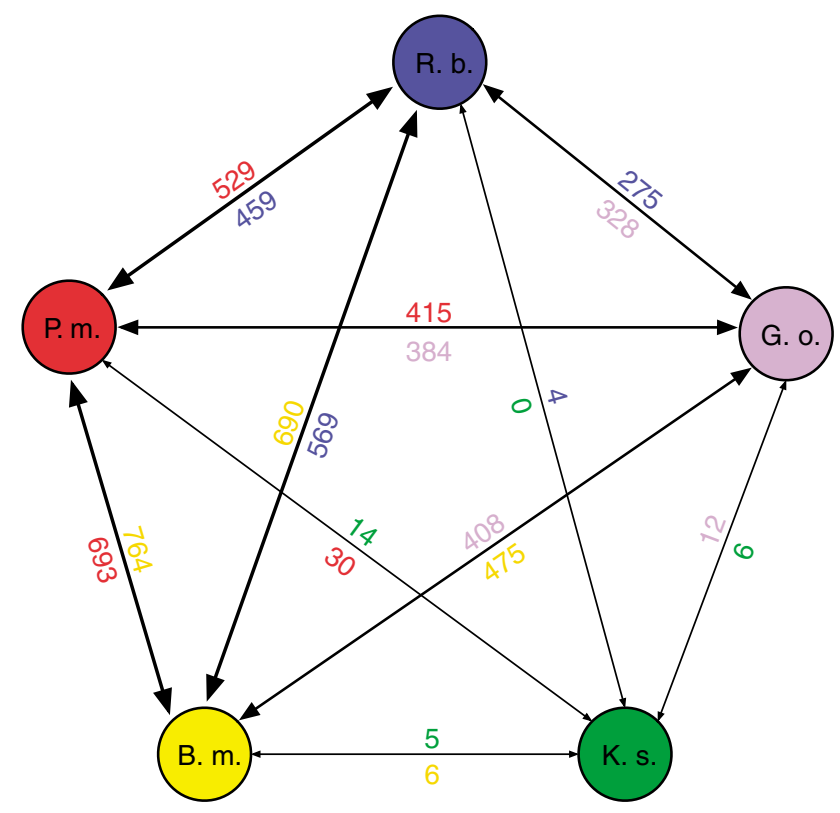

Figure 3 Genes for which BLAST hits below E-10 exclusively targeted Planctomycetes. Colors indicate the respective reference genome for the BLAST searches. Corresponding colors represent the number of hits in the respective target genome that is also expressed by thickness of the connection lines.

occurring in at least one other Planctomycete species, vastly diverging numbers were obtained (Figure 3). The genomes of $R$. baltica $\mathrm{SH} 1^{\mathrm{T}}$, P. maris DSM $8797^{\mathrm{T}}$ and $B$. marina DSM $3645^{\mathrm{T}}$ were found to share 429-764 genes, while G. obscuriglobus UQM $2246^{\mathrm{T}}$ was more distant to these three with $275-475$ shared genes. In Candidatus K. stuttgartiensis finally, merely 0-30 planctomycete-specific genes were found that were shared with at least one of the other four planctomycetes.

All five investigated genomes contained high proportions of hypothetical proteins of which large fractions were found to be orphaned, that is present only in one particular planctomycete with no known homolog in any other species (Table 2).
On all six sequenced fosmids, 26 out of 183 genes with reliable BLAST hits exclusively to Planctomycetes were found (Table 5). It is noteworthy that from these 26 planctomycete-specific genes, only a single one exhibited high similarity to a gene from Candidatus K. stuttgartiensis. As with the genome sequences, many of the planctomycete-specific genes on the fosmids contained the Pfam domains DUF1501, DUF1550 and DUF1559, and co-occurrences of the domains DUF1549 and DUF1533. Expression analysis of the closest homologs (BLAST) to these planctomycete-specific genes in glucose-grown $R$. baltica $\mathrm{SH} 1^{\mathrm{T}}$ revealed two expressed genes, one homolog to 3FN_15 carrying a weak hit to a prenyltransferase repeat domain and one homolog to 8FN_23 that harbors a DUF1559 domain (Table 5).

\section{Sulfatases}

The number of genes encoding sulfatases varied considerably among the different Planctomcetes investigated (Table 2). While the marine planctomycetes $R$. baltica SH $1^{\mathrm{T}}, P$. maris DSM $8797^{\mathrm{T}}$ and $B$. marina DSM $3645^{\mathrm{T}}$ encode high numbers of sulfatases, only few sulfatases could be found in the nonmarine planctomycetes $G$. obscuriglobus UQM $2246^{\mathrm{T}}$ and 'Candidatus K. stuttgartiensis'.

$R$. baltica $\mathrm{SH} 1^{\mathrm{T}}$ codes for no less than 109 sulfatases (15.3 per Mb), which to date is the highest number found in any bacterial genome. In the $P$. maris DSM $8797^{\mathrm{T}}$ draft genome we found 87 sulfatases $(10.7 / \mathrm{Mb})$ and in the one of $B$. marina DSM $3645^{\mathrm{T}} 41(6.16 / \mathrm{Mb})$, whereas in the $G$. obscuriglobus UQM $2246^{\mathrm{T}}$ draft sequence only 12 sulfatases were found (1.3/Mb) and in Candidatus K. stuttgartiensis only three $(0.7 / \mathrm{Mb})$. Additionally, one sulfatase could be found on fosmid 6FN (orf 6FN_6) from the Namibian upwelling system and one on fosmid 5H12 (orf 5H12_13) from the Oregon coast (Supplementary Tables 3 and 6). Using the whole-genome microarray, expression of the sulfatases with the best BLAST hits was checked in 
Table 5 Overview of planctomycete-specific genes and their domains of unknown function (DUFs) detected on the investigated fosmids

\begin{tabular}{|c|c|c|c|}
\hline Fosmid & Gene & Function & Observations \\
\hline \multirow[t]{5}{*}{$3 \mathrm{FN}$} & 3FN_13 & & \\
\hline & 3FN_15 & $\begin{array}{l}\text { Protein containing terpenoid cylases/protein prenyltransferase } \\
\text { alpha-alpha toroid domain }\end{array}$ & \\
\hline & $3 F N \_23$ & Protein containing DUF1549, DUF1553 & \\
\hline & 3FN_25 & Protein containing DUF1501, secreted & \\
\hline & 3FN_26 & Protein containing DUF1549, DUF1553, secreted & \\
\hline \multirow[t]{4}{*}{$6 \mathrm{FN}$} & 6FN_5 & & \\
\hline & 6FN_20 & Protein containing DUF1501, secreted & \\
\hline & 6FN_21 & $\begin{array}{l}\text { Protein containing planctomycete cytochrome c domain, DUF1549 } \\
\text { and DUF1553, secreted }\end{array}$ & \\
\hline & $6 F N \_26$ & Protein containing DUF1550, membrane & $\begin{array}{l}\text { Hit also for } \\
\text { Candidatus K } \\
\text { stuttgartiensis }\end{array}$ \\
\hline \multirow[t]{4}{*}{$8 \mathrm{FN}$} & 8FN_8 & Protein containing DUF1501, secreted & \\
\hline & 8FN_9 & & \\
\hline & 8FN_23 & Protein containing DUF1559 & \\
\hline & 8FN_33 & Protein kinase superfamily protein, membrane & \\
\hline $13 \mathrm{FN}$ & 13FN_31 & & \\
\hline \multirow[t]{3}{*}{$6 \mathrm{~N} 14$} & 6N14_18 & & \\
\hline & 6N14_21 & & \\
\hline & $6 \mathrm{~N} 14 \_25$ & & \\
\hline \multirow[t]{9}{*}{$5 \mathrm{H} 12$} & 5H12_7 & & \\
\hline & 5H12_8 & & \\
\hline & $5 \mathrm{H} 12 \_9$ & Protein containing DUF1501 & \\
\hline & $5 \mathrm{H} 12 \_10$ & Protein containing DUF1553 & \\
\hline & 5H12_11 & & \\
\hline & 5H12_17 & & \\
\hline & 5H12_25 & & \\
\hline & $5 \mathrm{H} 12 \_26$ & & \\
\hline & $5 \mathrm{H} 12 \_29$ & & \\
\hline
\end{tabular}

glucose-grown $R$. baltica $\mathrm{SH} 1^{\mathrm{T}}$. While the homolog to the sulfatase on fosmid $6 \mathrm{FN}$ did not show detectable levels of expression, the homolog on fosmid $5 \mathrm{H} 12$ was clearly expressed.

\section{Discussion}

In the present study, six Planctomycete fosmid insert sequences from two different marine upwelling systems were compared with all available complete or almost complete Planctomycete genomes. Taking the two new draft genomes of $B$. marina DSM $3645^{\mathrm{T}}$ and $P$. maris DSM $8797^{\mathrm{T}}$ into account, we now have genomic information from all described Planctomycete genera at hand except of the Isosphaera and Pirellula lineage.

R. baltica SH $1^{\mathrm{T}}$ and B. marina DSM $3645^{\mathrm{T}}$ were both isolated from the Kiel Fjord in the Baltic Sea (Schlesner, 1994) and are aerobic heterotrophs. They are marine representatives of the Planctomycete phylum, since they do not grow in freshwater media (Schlesner et al., 2004). P. maris DSM $8797^{\mathrm{T}}$ was isolated from shallow waters at Puget Sound, Washington, USA (Bauld and Staley, 1976, 1980) and is a heterotrophic, aerobic, marine plancto- mycete as well. G. obscuriglobus UQM $2246^{\mathrm{T}}$ is a freshwater isolate from the Maroon Dam in Queensland, Australia (Franzmann and Skerman, 1984) and Candidatus K. stuttgartiensis was enriched from a wastewater treatment plant in Stuttgart, Germany (Schmid et al., 2000).

\section{Environmental function of Planctomycetes}

The planctomycetes from marine habitats contained considerably higher sulfatase copy numbers in their genomes than the planctomycetes from freshwater habitats (Table 2). Likewise, one of the four fosmid sequences from the Namibian upwelling system and one of the two fosmids from the Oregon upwelling each contained one sulfatase. Moreover, recently a planctomycete fosmid was published from the North Pacific Subtropical Gyre (fosmid HF10_49E08, GenBank EF089402, $39.2 \mathrm{~kb}$ ) that besides a proteorhodopsin contained no less than six sulfatases (McCarren and Delong, 2007). All these fosmids together amount to $\sim 272 \mathrm{~kb}$ of sequence information with an average of 22 sulfatases per $\mathrm{Mb}$. This exceeds even the sulfatase density observed within $R$. baltica $\mathrm{SH} 1^{\mathrm{T}}$, the marine planctomycete with the highest number of sulfatase encoding genes 
known so far (Table 2). The presence of high sulfatase gene numbers might be attributed to a particular marine lifestyle. The most likely candidate substrates for these sulfatases are sulfated heteropolysaccharides, which are produced in large quantities in marine environments, for example by fish (chondritin in cartilage), red algae (agars and carrageenans) and brown algae (sulfated fucans). These compounds are of a great chemical complexity, and hence require a versatile repertoire of specific sulfatases for successful biodegradation, which explains the high sulfatase numbers within marine Planctomycete genomes.

We proposed earlier that sulfated polysaccharides are entrapped in marine snow aggregates, which are known to be colonized by planctomycetes. Sulfatase-rich planctomycetes are then supposed to be able to degrade these polysaccharides and subsequently use their carbon skeletons as an energy source (Glöckner et al., 2003). Sulfatase activity has meanwhile been proven for R. baltica SH $1^{\mathrm{T}}$, and not only for linear but also for sterically demanding sulfated compounds (Wallner et al., 2005). In addition, it has been demonstrated that $R$. baltica SH $1^{\mathrm{T}}$, while apparently not capable of degrading agar, does degrade carrageenan (Gurvan Michel, personal communication). Likewise, expression profiling showed that some of the sulfatases in $R$. baltica SH $1^{\mathrm{T}}$ are expressed. This fits perfectly to the aforementioned proposed lifestyle for these organisms. A more in-depth analysis of the sulfatases in $B$. marina DSM $3645^{\mathrm{T}}$ revealed that 39 of its sulfatases carried the essential canonical motif [CS]-x-[PA]-x-R (Dierks et al., 1999; Berteau et al., 2006), which in 37 cases could be extended to [CS]-x-[PA]-x-R-x(4)[ST]-G. Thirty-four of these proteins had a proline at the third motif position, whereas four had a proline to alanine mutation. It is unclear whether this has any impact on the functioning or specificity of the respective enzymes, but the presence of the canonical motif indicates that these sulfatases are active. Considering the sheer amount of sulfated heteropolysaccharides that are produced in marine environments and the ubiquity of lateral gene transfer (LGT), it is highly unlikely that only representatives of the marine Planctomycetes have adapted to exploit this resource. Hence, it can be expected that high sulfatase gene numbers will be discovered in marine representatives from other lineages as well and likely play an important role in highly productive marine upwelling systems.

It was one of the most surprising findings in previous studies of the genomes of $R$. baltica SH $1^{\mathrm{T}}$ and the draft genome of $G$. obscuriglobus UQM $2246^{\mathrm{T}}$ that both code for proteins involved in tetrahydromethanopterin-( $\left.\mathrm{H}_{4} \mathrm{MPT}\right)$-linked C1-compound conversions (Supplementary Figure 2) and the biosynthesis of the associated essential cofactor methanopterin (Glöckner et al., 2003; Bauer et al., 2004; Chistoserdova et al., 2004). In subsequent studies, it could be demonstrated that such C1 genes are present in further uncultivated planctomycetes (Kalyuzhnaya et al., 2005a,c). Before, these genes were believed to occur only in methanogenic and sulfate-reducing Archaea, and in methylotrophic Alpha-, Beta- and Gammaproteobacteria, where they play the central role in either the reductive or oxidative gain of energy from C1-substrates and in the detoxification of the hazardous metabolic intermediate formaldehyde (Chistoserdova et al., 1998; Vorholt et al., 1999; Marx et al., 2003). Many of the $\mathrm{H}_{4}$ MPT-linked $\mathrm{C} 1$ genes have been identified by functional studies on the methylotroph Methylobacterium extorquens AM1 (Chistoserdova et al., 2005) with the notable exception of $O R F 1$, which is absent in $M$. extorquens AM1 but present in various other methylotrophs (see Supplementary Table 1 for an overview on the functions).

The parallel presence of $\mathrm{H}_{4}$ MPT-dependent genes in representatives of the Archaea, Proteobacteria and Planctomycetes has led to numerous theories about the origin and evolution of these genes (Bauer et al., 2004; Chistoserdova et al., 2004). One scenario assumes two LGT events by which the genes were first passed on from Archaea to Proteobacteria and from there to the Planctomycetes. Another scenario presumes that the last universal common ancestor was already equipped with C1-transfer genes, but that these genes were only preserved within few lineages during the microbial evolutionary radiation. This scenario is supported by a screening of the Sargasso Sea data set showing that $\mathrm{H}_{4}$ MPT-dependent genes occur in additional unknown bacterial lineages and thus are more wide-spread (Kalyuzhnaya et al., 2005d). However, based on the present data it is not possible to decide between these alternate scenarios, especially since the phylogenetic position of the entire PVC superphylum is unclear. The easiest explanation would be to question the monophyly of the eubacteria, which has been proposed by Cavalier-Smith, (2006), but this discussion is clearly beyond the scope of this study.

Investigation of the studied planctomycete genomes and fosmids for genes involved in the conversion of $\mathrm{C} 1$ carbon compounds revealed that four of the genomes and two of the fosmids ( $8 \mathrm{FN}$ and $6 \mathrm{FN}$ ) contained such genes (Table 3 and Figure 2). The notable exception in the genomes is the deepbranching anammox bacterium Candidatus K. stuttgartiensis, which lacks those genes completely. Earlier studies discussed that the clustering of C1-transfer genes in Planctomycetes is much looser than in the genomes of methylotrophic proteobacteria where the genes are arranged in a few main clusters (Bauer et al., 2004; Kalyuzhnaya et al., 2005b). Our study with four planctomycete genomes containing these genes supports this finding. The genes were scattered widely over the genomes and at most five genes were arranged in one cluster (Figure 2). This cluster of Orf20-pabA-pabB-Orf19$m p t G$ was found on fosmid $8 \mathrm{FN}$ and in the genome 
of B. marina DSM $3645^{\mathrm{T}}$. Most likely, this cluster reflects the original organization of these genes in the Planctomycetes, and in the course of evolution it was split into smaller modules, as for example in P. maris DSM $8797^{\mathrm{T}}$, where these genes are organized in the two distinct clusters Orf20-pabA-pabB and Orf19$m p t G$. The study also supports the previously postulated clustering patterns of $\mathrm{C} 1$ genes in Planctomycetes, in particular clustering of $m p t G$ with orf19 and of mtdC with fae1 (Bauer et al., 2004; Kalyuzhnaya et al., 2005b). However, the previous observation that the $f m d A$, ftr and $f m d C$ are always co-located in all known bacterial genomes containing these Archaea-like genes (Bauer et al., 2004; Kalyuzhnaya et al., 2005b) could not be confirmed by the investigation of more Planctomycete genomes.

Up to now it has not been possible to answer the question whether these genes are functional in Planctomycetes and what role they play. So far, $R$. baltica $\mathrm{SH} 1^{\mathrm{T}}$ could not be shown to grow on C1 substrates (Bauer et al., 2004). On the other hand, codon usage analysis indicated high expression levels for fae1 in $R$. baltica SH $1^{\mathrm{T}}$ (Bauer et al., 2004) and in B. marina DSM $3645^{\mathrm{T}}$. Furthermore, proteome analysis proved that fae1, mtdC and mch are expressed in R. baltica SH $1^{\mathrm{T}}$ (Bauer et al., 2004), and our microarray experiments with glucose-grown $R$. baltica $\mathrm{SH} 1^{\mathrm{T}}$ cells have shown that even in the absence of an external C1 carbon source almost a third of the $\mathrm{C} 1$ genes in $R$. baltica $\mathrm{SH} 1^{\mathrm{T}}$ are expressed. Another indication that the genes involved in $\mathrm{H}_{4}$ MPT-dependent C1-compound conversions are active in the planctomycetes is their arrangement in conserved modules (Figure 2). In summary, this suggests that the respective pathway is of great physiological and environmental importance to these planctomycetes. It has been proposed that the sole role of these genes within the Planctomycetes is the detoxification of formaldehyde (Chistoserdova et al., 2004). However, to possess this pathway with its many steps solely as a means for formaldehyde detoxification does not seem to be necessary, since $R$. baltica $\mathrm{SH} 1^{\mathrm{T}}$, B. marina DSM $3645^{\mathrm{T}}$, P. maris DSM $8797^{\mathrm{T}}$ and G. obscuriglobus UQM $2246^{\mathrm{T}}$ contain glutathionedependent formaldehyde dehydrogenases and $R$. baltica $\mathrm{SH} 1^{\mathrm{T}}$ also contains a glutathione-independent formaldehyde dehydrogenase that can decompose formaldehyde in a much simpler way (Goenrich et al., 2002). Therefore, it seems likely that these C1 metabolism genes in Planctomycetes play an important role in an as yet unknown context. The presence of $\mathrm{C} 1$ metabolism genes in the fosmids from the Nambian upwelling region indicates that this pathway is of importance in the suboxic waters of this highly productive region. The presence of non-anammox plancomycetes in this region further implies that these planctomycetes can cope with low oxygen concentrations. This is also supported by the fact that all of the investigated Planctomycete genomes with the exception of Candidatus $\mathrm{K}$. stuttgartiensis harbor typical fermentation genes such as acetate/butyrate kinase or phosphoketolase. Nonetheless, these planctomycetes are considered as obligate aerobes since so far they have not been able to be cultivated under anoxic conditions.

All in all, the sulfatase-rich planctomycetes seem to be well adapted to the nutrient-rich conditions in marine upwelling systems and are also capable of thriving under oxygen-limiting conditions, which can occur seasonally (Oregon upwelling system) or permanently (OMZ of the Namibian upwelling system).

Features that set Candidatus K. stuttgartiensis and the other Planctomycetes apart

One striking result of our comparative genomics approach is the distinctness of 'Candidatus $\mathrm{K}$. stuttgartiensis'. It is almost completely devoid of genes that are shared with all other four investigated almost fully sequenced planctomycetes. In particular, the large paralogous gene families with otherwise planctomycete-specific domains that are even present on the small fosmids in this study are notably absent from 'Candidatus K. stuttgartiensis'. Even when the E-value threshold is lowered to E-10, there are only 11 of such genes. Likewise, when searched for planctomycete-specific genes that are not present in all but shared by at least two planctomycetes, there are only very few of these genes in 'Candidatus K. stuttgartiensis' (Figure 3). The same applies to the C1 carbon metabolism genes, which are absent from Candidatus K. stuttgartiensis but present in the four other almost fully sequenced planctomycetes, and also in the fosmids. As a consequence, the anammox bacteria have likely diverged at a very early stage from the last common planctomycete ancestor. The most parsimonious assumption is that this must have been before the radiation of planctomycete genera (Pirellula, Blastopirellula, Rhodopirellula, Planctomyces, Gemmata and Isosphaera), when the planctomycetespecific domains had not yet evolved and-if acquired by LGT-before the C1 metabolism genes were transferred. This is in agreement with phylogenetic studies based on 16S rRNA sequences and concatenated protein sequences, according to which anammox bacteria are deep branching within the Planctomycetes (Strous et al., 1999, 2006). However, the extent of the distinctness of 'Candidatus K. stuttgartiensis' is surprising. A distinctiveness of 'Candidatus K. stuttgartiensis' within the PVC superphylum was already indicated by Wagner and Horn (2006), who found a class of specific nucleotide transporters to be shared among the Chlamydiae and $R$. baltica $\mathrm{SH} 1^{\mathrm{T}}$ but notably absent from 'Candidatus K. stuttgartiensis'. Since the respective transporters are thought to be typical for endosymbionts and endoparasites, this could have wide implications for the evolution of the Planctomycetes and the anammox bacteria that are beyond 
the scope of this study. If the distinctness of the anammox bacteria is confirmed in the future by other anammox bacteria sequencing projects, one might consider whether a placement of the anammox bacteria within a separate phylum in the PVC superphylum is more appropriate.

\section{Functions of the planctomycete-specific genes}

So far one can only speculate on the functions of the planctomycete-specific genes reported here. Systematic investigations of their genetic neighborhoods did not lead to any conclusion concerning function. However, the sheer size of the paralogous gene families, in particular those of the Pfam domains DUF1501, PSCyt2, PSD1, PSCyt1 and SBP_bac_10, indicate that these genes are of great importance. It is noteworthy that these planctomycete-specific genes are often co-localized (Table 4). For example, DUF1559 genes are often followed downstream by a second planctomycete-specific gene of about $150 \mathrm{bp}$ that carries a signal peptide. Considering the high proportion of genes with signal peptides among the paralogous gene families, they might play a role in the context of planctomycete compartmentalization. Likewise, planctomycetespecific genes are frequently found at the beginning of operon-like gene arrangements, indicating a regulatory function. Interestingly, an unusually low number of transcriptional regulators has been reported for $R$. baltica SH $1^{\mathrm{T}}$ (Lombardot et al., 2005), and hence it is not unlikely that some of the planctomycete-specific paralogs act in the context of transcriptional control. Of course, further functional studies are required to validate these hypotheses.

\section{Conclusions}

This comprehensive comparative study of six planctomycete fosmids from marine upwelling regions and all available planctomycete genomic sequences allowed striking new insights in the fascinating phylum Planctomycetes. We were able to confirm the hypothesis that sulfatases are of particular importance for the lifestyle of many marine Planctomycetes and therefore are likely to be of general importance for the recycling of carbon from complex sulfated heteropolysaccharides in marine habitats. Furthermore, C1 metabolism genes were found on some of the fosmids and in all planctomycete genomes except for the anammox bacterium 'Candidatus Kuenenia stuttgartiensis'. This suggests a general relevance of these genes for Planctomycetes. In addition, very large families of planctomycetespecific paralogs were found that might serve as screening targets for Planctomycetes in flow-up studies. The notable lack of these genes within the only anammox planctomycete in this study reveals an as yet unknown distinctiveness of these organisms from all other Planctomycete genera.

\section{Acknowledgements}

The Gordon and Betty Moore Foundation (www.moore. org) has funded the almost complete sequencing of $B$. marina DSM $3645^{\mathrm{T}}$ and $P$. maris DSM $8797^{\mathrm{T}}$ within the framework of their Marine Microbiology Initiative. Furthermore, EFD is funded by a grant from the Gordon and Betty Moore foundation. Analysis of Rhodopirellula baltica $\mathrm{SH} 1 \mathrm{~T}$ is supported by the European Union through the Network of Excellence Marine Genomics Europe. Sequencing of $G$ obscuriglobus UQM 2246T is a collaboration between the group of Naomi Ward at The Institute for Genomic Research (www.tigr.org) and the group of John A. Fuerst at the University of Queensland, Australia and has been funded by the DOE (DoE grant DEFC0295ER61962). This study was funded by the Max Planck Society.

\section{References}

Asakawa S, Abe I, Kudoh Y, Kishi N, Wang Y, Kubota R et al. (1997). Human BAC library: construction and rapid screening. Gene 191: 69-79.

Badger JH, Olsen GJ. (1999). CRITICA: coding region identification tool invoking comparative analysis. Mol Biol Evol 16: 512-524.

Bauer M, Lombardot T, Teeling H, Ward NL, Amann RI, Glöckner FO. (2004). Archaea-like genes for C1transfer enzymes in Planctomycetes: phylogenetic implications of their unexpected presence in this phylum. J Mol Evol 59: 571-586.

Bauld J, Staley JT. (1976). Planctomyces maris sp. nov.: a marine isolate of the Planctomycetes-Blastocaulis group of budding bacteria. J Gen Microbiol 97: 45-55.

Bauld J, Staley JT. (1980). Planctomyces maris sp. nov., nom. rev. Int J Syst Bact 30: 657.

Berteau O, Guillot A, Benjdia A, Rabot S. (2006). A new type of bacterial sulfatases reveals a novel maturation pathway in prokaryotes. J Biol Chem 281: 2246422470.

Brochier C, Philippe H. (2002). Phylogeny: a non-hyperthermophilic ancestor for bacteria. Nature 417: 244.

Carbone A, Zinovyev A, Kepes F. (2003). Codon adaptation index as a measure of dominating codon bias. Bioinformatics 19: 2005-2015.

Cavalier-Smith T. (2006). Rooting the tree of life by transition analyses. Biol Direct 1: 19.

Chistoserdova L, Jenkins C, Kalyuzhnaya MG, Marx CJ, Lapidus A, Vorholt JA et al. (2004). The enigmatic planctomycetes may hold a key to the origins of methanogenesis and methylotrophy. Mol Biol Evol 21: 1234-1241.

Chistoserdova L, Rasche ME, Lidstrom ME. (2005). Novel dephosphotetrahydromethanopterin biosynthesis genes discovered via mutagenesis in Methylobacterium extorquens AM1. J Bacteriol 187: 2508-2512.

Chistoserdova L, Vorholt JA, Thauer RK, Lidstrom ME. (1998). C1 transfer enzymes and coenzymes linking methylotrophic bacteria and methanogenic Archaea. Science 281: 99-102.

Crump BC, Armbrust EV, Baross JA. (1999). Phylogenetic analysis of particle-attached and free-living bacterial communities in the Columbia river, its estuary, and the adjacent coastal ocean. Appl Environ Microbiol $S$ 65: 3192-3204. 
Delcher AL, Harmon D, Kasif S, White O, Salzberg SL. (1999). Improved microbial gene identification with GLIMMER. Nucleic Acids Res 27: 4636-4641.

DeLong EF, Franks DG, Alldredge AL. (1993). Phylogenetic diversity of aggregate-attached vs free-living marine bacterial assemblages. Limnol Oceanogr 38: 924-934.

Dierks T, Lecca MR, Schlotterhose P, Schmidt B, von Figura K. (1999). Sequence determinants directing conversion of cysteine to formylglycine in eukaryotic sulfatases. EMBO J 18: 2084-2091.

Fieseler L, Horn M, Wagner M, Hentschel U. (2004). Discovery of the novel candidate phylum 'Poribacteria' in marine sponges. Appl Environ Microbiol 70: 3724-3732.

Franzmann PD, Skerman VB. (1984). Gemmata obscuriglobus, a new genus and species of the budding bacteria. Antonie Van Leeuwenhoek 50: 261-268.

Fuerst JA, Gwilliam HG, Lindsay M, Lichanska A, Belcher C, Vickers JE et al. (1997). Isolation and molecular identification of planctomycete bacteria from postlarvae of the giant tiger prawn, Penaeus monodon. Appl Environ Microbiol 63: 254-262.

Fuerst JA, Sambhi SK, Paynter JL, Hawkins JA, Atherton JG. (1991). Isolation of a bacterium resembling Pirellula species from primary tissue culture of the giant tiger prawn (Penaeus monodon). Appl Environ Microbiol 57: 3127-3134.

Fuerst JA, Webb RI, Garson MJ, Hardy L, Reiswig HM. (1998). Membrane-bounded nucleoids in microbial symbionts of marine sponges. FEMS Microbiol Lett 166: $29-34$.

Fuerst JA, Webb RI, Garson MJ, Hardy L, Reiswig HM. (1999). Membrane-bounded nuclear bodies in a diverse range of symbionts of great Barrier Reef sponges. Mem Queensl Mus 44: 193-203.

Fuerst JA. (1995). The planctomycetes: emerging models for microbial ecology, evolution and cell biology. Microbiology 141: 1493-1506.

Fuerst JA. (2005). Intracellular compartmentation in planctomycetes. Annu Rev Microbiol 59: 299-328.

Gade D, Schlesner H, Glöckner FO, Amann R, Pfeiffer S, Thomm M. (2004). Identification of planctomycetes with order-, genus-, and strain-specific 16S rRNAtargeted probes. Microb Ecol 47: 243-251.

Giovannoni SJ, Godchaux Wr, Schabtach E, Castenholz RW. (1987b). Cell wall and lipid composition of Isosphaera pallida, a budding eubacterium from hot springs. J Bacteriol 169: 2702-2707.

Giovannoni SJ, Schabtach E, Castenholz RW. (1987a). Isosphaera pallida, gen. and comb. nov., a gliding, budding eubacterium from hot springs. Arch Microbiol 147: 276-284.

Glöckner FO, Kube M, Bauer M, Teeling H, Lombardot T, Ludwig W et al. (2003). Complete genome sequence of the marine planctomycete Pirellula sp. strain 1. Proc Natl Acad Sci USA 100: 8298-8303.

Goenrich M, Bartoschek S, Hagemeier CH, Griesinger C, Vorholt JA. (2002). A glutathione-dependent formaldehyde-activating enzyme (Gfa) from Paracoccus denitrificans detected and purified via two-dimensional proton exchange NMR spectroscopy. I Biol Chem 277: 3069-3072.

Guo FB, Ou HY, Zhang CT. (2003). ZCURVE: a new system for recognizing protein-coding genes in bacterial and archaeal genomes. Nucleic Acids Res 31: 1780-1789.
Inagaki F, Nunoura T, Nakagawa S, Teske A, Lever M, Lauer A et al. (2006). Biogeographical distribution and diversity of microbes in methane hydrate-bearing deep marine sediments on the Pacific ocean margin. Proc Natl Acad Sci USA 103: 2815-2820.

Jetten MSM, Horn SJ, Van Loosdrecht MCM. (1997). Towards a more sustainable wastewater treatment system. Water SciTechnol 35: 171-180.

Jetten MSM, Schmid M, Schmidt I, Wubben M, van Dongen U, Abma W et al. (2002). Improved nitrogen removal by application of new nitrogen-cycle bacteria. Rev Environ Sci Biotechnol 1: 51-63.

Kalyuzhnaya MG, Bowerman S, Nercessian O, Lidstrom ME, Chistoserdova L. (2005c). Highly divergent genes for methanopterin-linked C1 transfer reactions in Lake Washington, assessed via metagenomic analysis and mRNA detection. Appl Environ Microbiol 71: 88468854.

Kalyuzhnaya MG, Korotkova N, Crowther G, Marx CJ, Lidstrom ME, Chistoserdova L. (2005b). Analysis of gene islands involved in methanopterin-linked C1 transfer reactions reveals new functions and provides evolutionary insights. J Bacteriol 187: 4607-4614.

Kalyuzhnaya MG, Lidstrom ME, Chistoserdova L. (2004). Utility of environmental primers targeting ancient enzymes: methylotroph detection in Lake Washington. Microb Ecol 48: 463-472.

Kalyuzhnaya MG, Nercessian O, Lapidus A, Chistoserdova L. (2005d). Fishing for biodiversity: novel methanopterin-linked C transfer genes deduced from the Sargasso Sea metagenome. Environ Microbiol 7: 19091916.

Kalyuzhnaya MG, Nercessian O, Lidstrom ME, Chistoserdova L. (2005a). Development and application of polymerase chain reaction primers based on $f h c D$ for environmental detection of methanopterin-linked C1metabolism in bacteria. Environ Microbiol 7: 12691274.

König E, Schlesner H, Hirsch P. (1984). Cell wall studies on budding bacteria of the Planctomyces/Pasteuria group and on a Prosthecomicrobium sp. Arch Microbiol 138: 200-205.

Krogh A, Larsson B, von Heijne G, Sonnhammer EL. (2001). Predicting transmembrane protein topology with a hidden Markov model: application to complete genomes. J Mol Biol S 305: 567-580.

Kuypers MM, Lavik G, Woebken D, Schmid M, Fuchs BM, Amann $\mathrm{R}$ et al. (2005). Massive nitrogen loss from the Benguela upwelling system through anaerobic ammonium oxidation. Proc Natl Acad Sci USA 102: 64786483.

Liesack W, König H, Schlesner H, Hirsch P. (1986). Chemical composition of the peptidoglycan-free cell envelopes of budding bacteria of the Pirellula/Planctomyces group. Arch Microbiol 145: 361-366.

Liesack W, Söller R, Steward T, Haas H, Giovannoni S, Stackebrandt E. (1992). The influence of tachytelically (rapidly) evolving sequences on the topology of phylogenetic trees-intrafamily relationships and the phylogenetic position of Planctomycetaceae as revealed by comparative analysis of $16 \mathrm{~S}$ ribosomal RNA sequences. Syst Appl Microbiol 15: 357-362.

Lindsay MR, Webb R, Fuerst JA. (1997). Pirellulosomes: a new type of membrane-bounded cell compartment in planctomycete bacteria of the genus Pirellula. Microbiology 143: 739-748. 
Lindsay MR, Webb RI, Strous M, Jetten MSM, Butler MK, Forde RJ et al. (2001). Cell compartmentalisation in planctomycetes: novel types of structural organisation for the bacterial cell. Arch Microbiol 175: 413-429.

Llobet-Brossa E, Rossello-Mora R, Amann R. (1998). Microbial community composition of Wadden Sea sediments as revealed by fluorescence in situ hybridization. Appl Environ Microbiol 64: 2691-2696.

Lombardot T, Bauer M, Teeling H, Amann R, Glöckner FO. (2005). The transcriptional regulator pool of the marine bacterium Rhodopirellula baltica $\mathrm{SH} 1 \mathrm{~T}$ as revealed by whole genome comparisons. FEMS Microbiol Lett 242: 137-145.

Ludwig W, Strunk O, Westram R, Richter L, Meier H, Yadhukumar et al. (2004). ARB: a software environment for sequence data. Nucleic Acids Res 32: 13631371.

Marx CJ, Chistoserdova L, Lidstrom ME. (2003). Formaldehyde-detoxifying role of the tetrahydromethanopterin-linked pathway in Methylobacterium extorquens AM1. J Bacteriol 185: 7160-7168.

McCarren J, Delong EF. (2007). Proteorhodopsin photosystem gene clusters exhibit co-evolutionary trends and shared ancestry among diverse marine microbial phyla. Environ Microbiol S 9: 846-858.

Meyer F, Goesmann A, McHardy AC, Bartels D, Bekel T, Clausen J et al. (2003). GenDB-an open source genome annotation system for prokaryote genomes. Nucleic Acids Res 31: 2187-2195.

Miskin IP, Farrimond P, Head IM. (1999). Identification of novel bacterial lineages as active members of microbial populations in a freshwater sediment using a rapid RNA extraction procedure and RT-PCR. Microbiology 145: 1977-1987.

Morris RM, Longnecker K, Giovannoni SJ. (2006). Pirellula and OM43 are among the dominant lineages identified in an Oregon coast diatom bloom. Environ Microbiol 8: 1361-1370.

Musat N, Werner U, Knittel K, Kolb S, Dodenhof T, van Beusekom JE et al. (2006). Microbial community structure of sandy intertidal sediments in the North Sea, Sylt-Romo Basin, Wadden Sea. Syst Appl Microbiol 29: 333-348.

Neef A, Amann R, Schlesner H, Schleifer KH. (1998). Monitoring a widespread bacterial group: in situ detection of planctomycetes with 16S rRNA-targeted probes. Microbiology 144: 3257-3266.

Nielson H, Engelbrecht J, Brunak S, von Heijne G. (1997). Identification of prokaryotic and eukaryotic signal peptides and prediction of their cleavage sites. Protein Eng 10: 1-6.

Pace NR, Olsen GJ, Woese CR. (1986). Ribosomal RNA phylogeny and the primary lines of evolutionary descent. Cell S 45: 325-326.

Peden JF. (1999). Analysis of Codon Usage. PhD thesis, Department of Genetics, University of Nottingham.

Pimentel-Elardo S, Wehrl M, Friederich AB, Jensen PR, Henschel U. (2003). Isolation of planctomycetes from Aplysina sponges. Aquatic Microbial Ecol 33: 239-245.

Quast C. (2006). MicHanThi - design and implementation of a system for the prediction of gene functions in genome annotation projects. Master thesis (available on request).

Rabus R, Gade D, Helbig R, Bauer M, Glöckner FO, Kube M et al. (2002). Analysis of $\mathrm{N}$-acetylglucosamine meta- bolism in the marine bacterium Pirellula sp. strain 1 by a proteomic approach. Proteomics 2: 649-655.

Rusch A, Huettel M, Reimers CE, Taghon GL, Fuller CM. (2003). Activity and distribution of bacterial populations in middle Atlantic bight shelf sands. FEMS Microbiol Ecol 44: 89-100.

Rusch DB, Halpern AL, Sutton G, Heidelberg KB, Williamson S, Yooseph S et al. (2007). The sorcerer II global ocean sampling expedition: Northwest Atlantic through Eastern Tropical Pacific. PLoS Biol S 5: e77.

Schlesner H, Rensmann C, Tindall BJ, Gade D, Rabus R, Pfeiffer $S$ et al. (2004). Taxonomic heterogeneity within the Planctomycetales as derived by DNADNA hybridization, description of Rhodopirellula baltica gen. nov., sp. nov., transfer of Pirellula marina to the genus Blastopirellula gen. nov. as Blastopirellula marina comb. nov. and emended description of the genus Pirellula. Int J Syst Evol Microbiol 54: 15671580 .

Schlesner H. (1994). The development of media suitable for the microorganisms morphologically resembling Planctomyces spp., Pirellula spp., and other Planctomycetales from various aquatic habitats using dilute media. Syst Appl Microbiol 17: 135-145.

Schmid M, Twachtmann U, Klein M, Strous M, Juretschko S, Jetten MSM et al. (2000). Molecular evidence for genus level diversity of bacteria capable of catalyzing anaerobic ammonium oxidation. Syst Appl Microbiol 23: 93-106.

Scott JW, Rasche ME. (2002). Purification, overproduction, and partial characterization of beta-RFAP synthase, a key enzyme in the methanopterin biosynthesis pathway. J Bacteriol S 184: 4442-4448.

Sinninghe Damsté JS, Strous M, Rijpstra WI, Hopmans EC, Geenevasen JA, van Duin AC et al. (2002). Linearly concatenated cyclobutane lipids form a dense bacterial membrane. Nature $S$ 419: 708-712.

Stackebrandt E, Ludwig W, Schubert W, Klink F, Schlesner $\mathrm{H}$, Roggentin $\mathrm{T}$ et al. (1984). Molecular genetic evidence for early evolutionary origin of budding peptidoglycan-less eubacteria. Nature 307: 735-737.

Staley JT, Bouzek H, Jenkins C. (2005). Eukaryotic signature proteins of Prosthecobacter dejongeii and Gemmata sp. Wa-1 as revealed by in silico analysis. FEMS Microbiol Lett 243: 9-14.

Stein JL, Marsh TL, Wu KY, Shizuya H, DeLong EF. (1996). Characterization of uncultivated prokaryotes: isolation and analysis of a 40-kilobase-pair genome fragment from a planktonic marine archaeon. J Bacteriol $S \mathbf{1 7 8}$ : 591-599.

Strous M, Fuerst JA, Kramer EH, Logemann S, Muyzer G, van de Pas-Schoonen KT et al. (1999). Missing lithotroph identified as new planctomycete. Nature 400: 446-449.

Strous M, Pelletier E, Mangenot S, Rattei T, Lehner A, Taylor MW et al. (2006). Deciphering the evolution and metabolism of an anammox bacterium from a community genome. Nature 440: 790-794.

Studholme DJ, Fuerst JA, Bateman A. (2004). Novel protein domains and motifs in the marine planctomycete Rhodopirellula baltica. FEMS Microbiol Lett 236: 333-340.

Teeling H, Lombardot T, Bauer M, Ludwig W, Glöckner FO. (2004). Evaluation of the phylogenetic position of the planctomycete 'Rhodopirellula baltica' $\mathrm{SH} 1$ by means of concatenated ribosomal protein sequences, DNA-directed RNA polymerase subunit sequences 
and whole genome trees. Int J Syst Evol Microbiol 54: 791-801.

Tekniepe BL, Schmidt JM, Starr MP. (1981). Life cycle of a budding and appendaged bacterium belonging to morphotype IV ofthe Blastocaulis-Planctomyces group. Curr Microbiol 5: 1-6.

Vergin KL, Urbach E, Stein JL, DeLong EF, Lanoil BD, Giovannoni SJ. (1998). Screening of a fosmid library of marine environmental genomic DNA fragments reveals four clones related to members of the order Planctomycetales. Appl Environ Microbiol 64: 30753078.

Vorholt JA, Chistoserdova L, Stolyar SM, Thauer RK, Lidstrom ME. (1999). Distribution of tetrahydromethanopterin-dependent enzymes in methylotrophic bacteria and phylogeny of methenyl tetrahydromethanopterin cyclohydrolases. J Bacteriol 181: 5750-5757.

Vorholt JA, Kalyuzhnaya MG, Hagemeier CH, Lidstrom ME, Chistoserdova L. (2005). MtdC, a novel class of methylene tetrahydromethanopterin dehydrogenases. J Bacteriol 187: 6069-6074.
Wagner M, Horn M. (2006). The Plantomycetes, Verrucomicrobia, Chlamydiae and sister phyla comprise a superphylum with biotechnological and medical relevance. Curr Opin Biotechnol 17: 241-249.

Wallner SR, Bauer M, Würdemann C, Wecker P, Glöckner FO, Faber K. (2005). Highly enantioselective secalkyl sulfatase activity of the marine planctomycete Rhodopirellula baltica shows retention of configuration. Angew Chem Int Ed Engl 44: 63816384.

Wang J, Jenkins C, Webb RI, Fuerst JA. (2002). Isolation of Gemmata-like and Isosphaera-like planctomycete bacteria from soil and freshwater. Appl Environ Microbiol 68: 417-422.

Weisburg WG, Hatch TP, Woese CR. (1986). Eubacterial origin of Chlamydiae. J Bacteriol 167: 570-574.

Woese CR. (1987). Bacterial evolution. Microbiol Rev S 51: 221-271.

Zhou J, Bruns MA, Tiedje JM. (1996). DNA recovery from soils of diverse composition. Appl Environ Microbiol S 62: $316-322$.

Supplementary Information accompanies the paper on The ISME Journal website (http://www.nature.com/ ismej) 